\title{
An empirical analysis of the driving forces of forest cover change in northeast China
}

\author{
Miaoying Shi ${ }^{1}$ Runsheng Yin ${ }^{2,}{ }^{*}{ }^{*}$ Hongdi $\mathbf{L v}^{3}$ \\ 1 Department of Forestry, Michigan State University, East Lansing, MI 48824, USA \\ shimiaoy@msu.edu \\ 2 College of Economics and Management, Northwest A\&F University, Yangling712100, China \\ ${ }^{3}$ Chinese Academy for Environmental Planning, Beijing 100012,China \\ lvhd@caep.org.cn \\ * Correspondence: yinr@anr.msu.edu; Tel.: +1-517-432-3352
}

\section{Introduction}

China's forest sector has undergone tremendous changes since the mid-twentieth century (Yin, 1998; Yin et al., 2003; Zhang, 2001). In the northeast, the growth of logging and forest products manufacturing and the expansion of farming and local economy, among other things, depleted a vast number of natural forests (Xu et al., 2004; Zhang et al., 2000). Yu et al. (2011) reported that about a half of the matured stands there disappeared in less than 20 years(from 1981to 1998), with the stocking volume falling from 1,660 million $\mathrm{m}^{3}$ to 860 million $\mathrm{m}^{3}$. Within the region, Heilongjiang, due to its rich endowment of natural forests, used to be a primary province of timber production in the country (SFA, 2005; Yu et al., 2011). However, it suffered heavy deforestation and forest degradation (MOF, 1997). Jiang et al. (2014)showed that its proportion of mature timber stock decreased from $65.6 \%$ in 1984 to only $3.2 \%$ in 2004 . These problems caused serious soil erosion, water shortages, and habitat losses (Jiang et al., 2014; Xu et al., 2005; Yin and Yin, 2010). 
At the turn of the $21^{\text {st }}$ century, the central government was compelled to take drastic measures to halt the deforestation and improve its forest conditions (Xu et al., 2004; Zhang et al., 2000). The Natural Forest Protection Program (NFPP) was thus launched in 2000, with an initial investment of 96 billion Yuan $^{1}$ in its first phase (until 2010) to ban or substantially reduce commercial logging while conserving nearly 90 million ha of natural forests and to reforest and re-vegetate an additional 8.7 million ha (Shen et al., 2006; Yin and Yin, 2010). The program is now well into its second phase for the period of 2010-2020 with a commitment of another 244 billion Yuan. In addition to banning commercial logging completely, it aims to promote forest management and revitalize local economies (NFPP Management Center, 2011). Hence, it is interesting and important to investigate the determinants of the fate of the forest ecosystems in northeast China, which is what we intend to accomplish in this study.

There have been studies of the driving forces of forest dynamics in general and the effectsof the NFPP in particular. Using Qinhe Forest Bureau in Heilongjiang as a case,Xu et al. (2005)assessed the preliminary economic impacts of the NFPP. They showed that from 1998 to 2001, logging and processing earnings, together with local taxrevenues, had declined sharply. Meanwhile, the income of employees in the forest bureau was improved. As this study was done soon after the program was initiated, the data used were insufficient to support a more comprehensive analysis. Zhang et al. (2011), using a repeated cross-sectional dataset of 35 forest farms over three points of time (2000, 2003, and 2006) in northeast China, examined the forest condition changes in terms of new plantation area, area under strict protection, and timber harvest volume. They found that the NFPP had positive effects, assuming that the geographic and socioeconomic characters across all the forest farms would be homogenous.

\footnotetext{
${ }^{1}$ \$1 US is roughly 6.7 Chinese Yuan as of July 25, 2016.
} 
Later, Huang et al. (2010)relaxed the homogeneity assumption and concluded differently. They formulated three regression equations in a structural model to explore the causes of forest changes in northeast China from 1985 to 2005, claiming that such socioeconomic factors as total population, rural population, and GDP, had each played a substantive role. Moreover, geographic and meteorological indicators, like terrain slope, elevation, and climate conditions, weredeemed to be factors influencing the forest condition. While the empirical results are interesting, its analytical framework is problematic because of the lack of atheoretical foundation and the arbitrary selection of variables.

Mullan et al. (2009) analyzed the NFPP impact on local household income and labor decision, employing a difference-in-differences method and two-period survey data (1997 and 2004) from rural communities. Their results suggested that the program had negatively affected the income of timber harvesting; but it had stimulated more off-farm labor supply in the program areas compared to the non-program areas and made a positive impact on household total income. Nonetheless, the data from only two points of time in the early stage of the first phase of the program did not allow the authors to capture itslonger-term effect. Another potential issue is that the recall databefore initiating the NFPP may not be equally reliable.Jiang et al. (2014) presented an integrated theoretical and empirical analysis of the harvest and investment behavior of stateowned forest enterprises (SOFEs). Usinga dataset of 75 SOFEs in northeast China during 19802004, they demonstrated that policy measures could have had positive effects on the development of forest resources through changing the managerial behavior. Due to the rigidity of undertaking any significant reform of the employment and social servicesystems, however, the SOFEs "have had relatively few effects on harvest and investment decisions, and on development of the forest resources.” 
These and other studies have provided useful background information and interesting case descriptions regarding the NFPP impact and the forest dynamics in northeast China.However, theyseem limited in analytic scope and rigor. First, the case studies are largely based on survey statistics often within a short time span. As a result, there has not been a clear and careful characterization of the long-term trajectory of the forest resources, which is essential to fully understand the historical deforestation and forest degradation and the potential recent forest recovery induced by implementing the NFPP. Second, despite the inherent linkages between different land uses, there has been little work that incorporates other land categories into the study of forest dynamics (Jiang et al., 2014; Mullan et al., 2009; Zhang et al., 2011). Further, previous studies have rarely utilized longitudinal data with consecutive observations that integrate both biophysical and socioeconomic information. Consequently, the forest cover changesand factors influencing these changes remain poorly understood.The goal of this paper is to assess the impacts of the NFPP and other factors on the forest condition in a theoretically sound and empirically appropriate manner.

Specifically, we will investigate the interactions and feedbacks between the drivers of changes in forest cover and other landusesby building a novel longitudinal dataset and adopting a multi-step modeling strategy. Thelongitudinal dataset will assimilate land-use and land-cover change (LULCC) information,which is derived by interpreting satellite imagery,and socialeconomic statistics across eight counties in Heilongjiang over a period of 37 years. The modeling strategy will tackle the inherent endogeneity embedded in the land-use changes and capture the effects of such factors as demographic change, economic development, and management transition on the forest condition. The intermittent LULCC data will be interpolated to obtain annual observationsand matched with existing annual indicators of socioeconomic conditions for 
each sample county to enable more sophisticated econometric modeling attempts to better understanding the linkages between social-ecological factors and forest dynamics. To validate the robustness of the results, a number of identification, endogeneity, and instrumentation tests will be conducted.It is hoped that, with the empirical data, modeling strategy, and testing

procedures used, this study will improve our knowledge of the resource dynamics and environmental consequences and their socioeconomic, policy, and other drivers, which will lead to more effective policy making and implementation and, ultimately, better resource conditions.

The paper is organized as follows. We describe the methods in section 2 and the data and variableselection in section 3. Empirical results,as well as the between-model comparisons of these results, are then presented in section 4. Finally, the implications of analysis of forest dynamics drivers are discussed in section 5.

\section{Theory and methods}

Shi et al. (2016) have documented the land use dynamics during 1977-2013. With minor classes being merged, their classification work features four land-use classes-forestland, farmland, built-up, and other land. Their detection results demonstrate that: (1) farmland and forestland were the two predominant classes of the regional land use; (2) forestland suffered an extended, heavy loss before the end of last century and the decline slowed down significantly thereafter; (3) other land (mainly wetland) declined continuously as well; and (4) built-up land increased persistently during the 37 years (see Figure 1 below for detail). Basedon extended conversion matrices, the authors further reveal the following dominant land transition rules: (1) heavy and continuous losses of forestland and wetland were mainly driven by farmland expansion; (2) while forestland experienced the largest lossin absolute terms, wetland suffered the biggest 
reductionin proportion; and (3) built-up landencroached virtually exclusively on farmland. Figure 2 below summarizes these major trends of land conversions.

\section{$<$ Insert Figure 1 and Figure 2 here $>$}

The complex interactionsbetween these land uses suggest that potential endogeneity could have arisen from: (1) simultaneity intrinsic in land-use conversions over time; and (2) possible indirect or spillover effects induced by other land-use changes (Brownstone et al., 2002; Semykina and Wooldridge, 2010). So, characterizing endogenous land-use changes becomes not only desirable but also necessary in our analysis of their drivers (Baltagi, 2006; Fingleton and Gallo, 2007; Jöreskog and Sörbom, 1986). Endogeneity usually refers to situations where

nonzero correlation exists between the error terms and certain explanatory variables in a regression model (Chenhall and Moers, 2007; Louviere et al., 2005). If certain explanatory variables are not independent but influenced by other variables within the system, they can lead to biased or inconsistent parameter estimates, making reliable inference impossible (Semykina and Wooldridge, 2010).

While endogeneity and the associated potentially biased estimation are well accounted for in econometrics (Angrist and Krueger, 2001; Angrist et al., 1996; Epple, 1987), econometrics has been slow to adopt the idea of endogeneity testing and correction in analyzing the forces driving LULCC (Irwin and Geoghegan, 2001; Lambin et al., 2001; Verburg et al., 2004). Even as of now, it is still rare to find studies linking LULCC to socioeconomic determinants with a careful handling of endogenous variables (Chomitz and Gray, 1996; Herbert and Arild, 2009; Mertens and Lambin, 2000; Pfaff, 1999; Yin and Xiang, 2010).Conceptually, two alternatives exist to estimate an econometric model consistently when endogeneity is present—singleequation estimation with instrumental variables (IV) and system of equations estimation. In the 
following two subsections, we will first define a single equation model with IV to examine linkages between the two dominate land-use classes_-forestland and farmland; then, we will specify a system of three simultaneous equations (SEM) to depict the relevant LULCC relationships.

\subsection{Analysis of the two dominant land-use classes: an instrumental variable method}

Building on the recent advancement in land change science (Angelsen and Kaimowitz, 1999; Geist and Lambin, 2002; Kaimowitz and Angelsen, 1998; Lambin et al., 2001; Turner et al., 2008)and the history of forest transition in northeast China (Xu et al., 2006; Yu et al., 2011; Zhang et al., 2011; Zhang et al., 2000), Shi (2016) has presented a solid starting point to specify a regression model of the driving forces of forest dynamics in northeast China. Following that study, we will consider farmland (Fm) expansion as the main direct cause for deforestation here. The regional forest sector witnessed heavy logging and thus resource degradation in the 1980s and 1990s and then the initiation of the NFPP $(N)$ by the turn of the century (Yin et al., 2005). So, year 2000 could be a turning point of the management policy affecting forestland use (Yin and Yin, 2009).

Timber price (Tp) can be another important incentive influencing the behavior of forest enterprises and farmers and thus the forest condition. Low price could make profit-orientated farmers switch their production efforts from logging to cropping (Yin and Newman, 1996; Yin et al., 2003) and also cause the forest entities to neglect their management duties (Yin, 1998). Thus, timber price would affect the aggregate timber supply as well as local timber inventories; and, coupled with excessive logging, this situation could even lead to the deterioration of forest resources and subsequently impact the status of LULCC(Lambin et al., 2001). 
The study done by Geist and Lambin (2002) revealed that 102 out of 152 cases of deforestation were related to wood extraction, including government-sanctioned timber harvests and local farmers' consumption of fuelwood as well as construction timber. In general, selective wood extraction alone would not necessarily lead to deforestation because it does not necessarily result in a dramatic loss of canopy cover (Mainardi, 1998; Rudel and Roper, 1997). However, the impact of wood extraction is likely to become more pronounced over time, and studies found that wood production and deforestation are positively correlated (Asner et al., 2006; Asner et al., 2005; Bekker and Ploeg, 2005; Burgess, 1993). As direct measures of wood extraction are not available in our study region, we will use the gross output value of forestry $(O)$ as a proxy.Also, we assume that a shorter distance and thus lower transportation cost facilitates wood extraction and the growth of annual crops by local farmers, and even makes it possible to convert other kinds of land use into farmland. More specifically, we will take both distance $(D)$ from the forest farm to the nearby timber market as well as their county seats as a proxy measure of transport costs.

The stated-owned enterprises followed specific regulations imposed by the central government, such as the harvest and reforestation quotas (Xu et al., 2004). We will include the numbers of government-owned forest farms ( $\mathrm{Nf}$ ) in our model based on the assumption that the more clustered the forest farms are in a county, the larger their aggregate effect is in protecting forests from farmland encroachment (Key and Runsten, 1999).

Further, population $(P)$ is one of the most often used underlying factors in land-use change analyses. The widely recognized population effects on LULCC are mainly through the direct actions of clearing land for shelter and creating demand for forest products (Carr et al., 2005; Geist and Lambin, 2002). As local population grew and spread, more farmland was 
converted into built-up area; and clearing patches of forest for farming is inevitable to meet local farmers' production needs. Also, population growth is closely linked to a risein wood products consumption and fuelwood demand.

From the perspective of agriculture, farmland expansion is an extension of cultivation onto previously uncultivated areas. This process may require increased inputs, including 1) increased labor use for land conversion (e.g., construction of swamp drainage and irrigation channels) and cultivation, 2) increased spending on purchasing productionfactors, and 3) capital investment in technical capacityto raise land productivity (De Janvry et al., 1991; Färe et al., 1994; Grossman and Helpman, 1993; Kalirajan et al., 1996). In practice, the relative feasibility of these pathways is likely to vary in different areas. Of course, farmland expansion is in turn driven by an increased demand for food products, as partly reflected in their prices.

Specifically, we consider farmland $(F m)$ to be a function of agricultural population (a proxy for laborer, $L$ ), per capita annual net income $(C)$ (as a surrogate for potential farming expenditure), and total agricultural machinery power ( $T$ ) (a proxy for technological development). We will also include the price index of agricultural products $(A P)$ to reflect market demand change. Built-up area $(B)$ is another determinant of farmland growth given that more settlement tends to lead to greater agricultural expansion. With farmland expansion encroaching upon forestland $(F t)$, the equation of farmland use is linked to the equation of forestland as follows:

$$
\begin{aligned}
& F t_{i t}=f\left(F m_{i t}, T p_{t}, O_{i t}, N_{t}, D_{i}, N f_{i}, P_{i t}\right)+u_{i t} \\
& F m_{i t} \sim f\left(L_{i t}, C_{i t}, T_{i t}, A P_{t}, B_{i t}\right)+v_{i t}
\end{aligned}
$$

In both equations, $i$ denotes county and $t$ denotes time. If $i$ is not present in a variable, it means that county-level data are not available and provincial data are used instead; if a variable (e.g., distance to market), does not vary with time, $t$ is absent from the variable's subscript. Except for 
farmland in Eq. 1, the right-hand-side variables are independent. Farmland, on the other, is assumed to be endogenous and thus will be instrumented with a set of variables on the right side of Eq. 2.Recall that theland-use classification results suggested that both built-up land and farmland experienced a persistent expansion, but built-up land did not necessarily encroach onto forestland(Shi et al. 2016). With built-up area being an exogenous variable in particular, the strong correlation between farmland and built-up area makes it an important instrument candidate in Eq. 2. The error term, $u_{i t}$ represents the effects of the omitted variables that are peculiar to both the individual units and time periods. Under the fixed effects (FE) assumption, $u_{i t}$ is a combination of an independently identically distributed (i.i.d.) random error $\varepsilon_{i t}$ and an unobserved heterogeneity $\alpha_{i}$ peculiar to county $i$ over time (Hausman and Taylor, 1981; Nickell, 1981).

The instrumental variables method is applied as follows. The potentially endogenous variable (i.e., farmland) is first regressed on the included instrumental variables in Eq. 2 as well as all the exogenous variables in Eq. 1. Given the least squares regime, this first-stage regression produces an optimal linear combination of exogenous variables. Then, the predicted values of the endogenous variable are used as the independent variable in Eq. 1 in the second-stage regression (Murray, 2006; Wooldridge, 2002). As such, this procedure is also called the two-stage least squares, or 2SLS (Wooldridge, 2002). Coupledwith an FE estimator, the 2SLS regression model controls for not only the endogeneity in farmland but also unobserved heterogeneity.

\subsection{A more integrated system of land use: simultaneous equations}

Our study site has experienced a rapid expansion of rice production due to the high yield and good quality of the local rice(Jiang et al., 2006; Sun et al., 2010). Meanwhile, the acreage of 
other crops has declined significantly. For instance, based on the 15 farms surrounding the Honghe Natural Reserve in the Sanjiang Plain of Heilongjiang,Zhou et al. (2009) calculated that the rice fields increased from about $200 \mathrm{~km}^{2}$ in 1993 to more than $2000 \mathrm{~km}^{2}$ in 1998 . By 2002, the overall area of crop fields had reached $3,781 \mathrm{~km}^{2}$, of which paddy rice accounted for 2,024 $\mathrm{km}^{2}$. So, when characterizing the relationship of farmland demand and supply, agricultural production is a primary factor on the demand side, whereas forestland and wetland ("other" in our classification) are two main variables on the supply side. Also, since wetland is an alternative source of farmland expansion, it could act as a substitute for forestland. Therefore, it is worthwhile to adopt a more inclusive framework to identify the indirect linkages between wetland and forestland, in addition to the direct linkages between farmland and the other two classes of land use.

Below, we will define a system of three equations to represent the behavior of the three interrelated land-use classes - forestland, farmland, and wetland. Accordingly, these equations are namedthe forestland equation, farmland equation, and wetland equation. In the farmland equation, except for the instrumental variable-area of built-up land-we will first include the set of explanatory variables in Eq. 2 above and gradually drop those variables that have a weak relationship with farmland expansion. The rapid increase in paddy rice fields has propelled water demand in the Sanjiang Plain-pumping groundwater for irrigation; this has in turn led to a continual decline of groundwater level (Zhang et al., 2009). The establishment of extensive irrigation networks by local farmers has accelerated the wetland loss(Zhou et al., 2009). We will thus use the effective irrigation area to approximate the aggregate water use for irrigation.Also, natural events affect the status of wetland. For example, a warming climate and decreasing precipitation could possibly result in wetland reduction in the long run(Song et al., 2008; Yan et 
al., 2002; Zhang et al., 2010). We can thus define wetland status (Wt) as being associated with changes in farmland $(F m)$ and forest cover $(F t)$, human water withdrawal and reservoir construction (I), and climate change as reflected in decreased precipitation $(\mathrm{Pr})$ and increased temperature (T). This leads to Eq.5 below.

$$
\begin{array}{r}
F t_{i t}=f\left(F m_{i t}, W t_{i t}, T p_{t}, O_{i t}, N_{t}, D_{i}, N f_{i}, P_{i t}\right)+u_{i t} \\
F m_{i t}=f\left(L_{i t}, C_{i t}, T_{i t}, A P_{t}\right)+\varphi_{i t} \\
W t_{i t}=f\left(F m_{i t}, F t_{i t}, I_{t}, P r_{t}, T e_{t}\right)+\omega_{i t}
\end{array}
$$

Eq.3 and 4 are similar to Eq. 1 and 2 for the two dominant classes of land use, but an important distinction is that farmland change is instrumented with a set of candidate variables in Eq. 2, whereas those variables are now treated as regular regressors in Eq.4.

The above simultaneous equations allowfor possible interactions between some of the dependent variables. The three-stage least squares procedure (3SLS) will be used to estimate this system consistently and efficiently (Baltagi and Liu, 2009; Wooldridge, 1996). The concrete procedure consists of the following steps. First, convert the structural equations containing endogenous explanatory variables into reduced form equations, in which only exogenous variables appear on the right-hand side, and then estimate the reduced-form equations by OLS to obtain fitted values for the endogenous variables. Second, estimate the structural equation through 2SLS by replacing the endogenous regressors with their fitted values derived in step one and retrieve the covariance matrix of the equations disturbances. Finally, perform a generalized least square (GLS)-type estimation on the stacked system using the covariance matrix from the first step (Cornwell et al., 1992; Wooldridge, 1996).

\section{Data}


The sophisticated modeling attempts outlined above cannot be easily accommodated if we have only conventional cross-sectional or time-series data(Baltagi and Giles, 1998). For this study,we have built a longitudinal dataset spanning 37 yearsfor 8 counties: Suibin, Boli, Yilan, Fangzheng, Huanan, Huachuan, Qitaihe, and Jixian. ${ }^{2}$ The original LULCC data were derived from eight points of time $(1977,1984,1993,2000,2004,2007,2010$, and 2013) and they were then interpolated to obtain annual observations from 1977 to 2013.This temporal scale covers sufficient times both before and after the NFPP was launched, making our empirical findings potentially more relevant and robust.

Table 1 below presents a general description of all the variables. Those in bold are the three land-use classes (forestland, farmland, and wetland), which are taken as endogenous, and thus have their own explanatory variables. Details regarding the data sources of the variables and potential concerns about them are discussed below.

\section{$<$ Insert Table 1 here $>$}

Variables used in the forestlandequation Farmland $(F m)$ and forestland $(F t)$ are variables derived from the LULCC detection.They are the total areas $\left(\mathrm{km}^{2}\right)$ of each land uses, respectively. $\operatorname{NFPP}(N)$ is a discrete dummy variable, which takes value 0 before 2000 and 1 otherwise, indicating that the forest conservation program is "on" after 2000. Data for timber price $\left(T_{P}, \mathrm{yuan} / \mathrm{m}^{3}\right)$ came from the Forest Industry Bureau of Heilongjiang. The real price series was obtained by deflating the nominal prices with the provincial-level consumer price index (with a base year of 1976)(Heilongjiang Statistical Bureau, 1986-2014; Heilongjiang Statistics Bureau, 2009). Data for the gross output value of forestry (O) came from the Heilongjiang Statistical Yearbook, and the nominal output values were deflated with the GDP deflator (1976

\footnotetext{
${ }^{2}$ We wished to include more counties in sample, but the tremendous amount of work entailed in interpreting satellite images made it impossible.
} 
as the base year). Thenumber of forest farms ( $\mathrm{Nf}$ )in each county is included to explore the institutional effect, based on the assumption that with more government forest establishmentswithin a county, there would be less illegal logging and thus less deforestation.In case a forest farm is located in more than one county, we ascribed them to the county that contains the largest area. As local population $(P)$ increased and spread, more farmland was converted into built-up areas, and clearing forests for farming in order to increase farm productionbecame inevitable. Also, population growth is closely linked to rising consumption of wood products and fuelwood.The population data are from Heilongjiang Statistical Bureau (1986-2014) and Heilongjiang Statistics Bureau (2009). Mean distance(D)is used to measure the average distance from a forest farm to nearby county seats and timber markets.The data were generated by calculating the distances between the forest farm centroids to nearby 14 cities with a distance ranging up to $1000 \mathrm{~km}$. The 14 centroids include centers of the 10 county seats and the largest timber markets located close to the study region. These markets are in the cities of Harbin, Suifenghe, Jiamusi, and Mudanjiang.

Variables used in the farmlandequation Area of farmland was derived from land-use classification and data of the independent variables in the farmland equation all came from Heilongjiang Statistical Bureau (1986-2014) and Heilongjiang Statistics Bureau (2009). Number of Agricultural Population $(L)$ is a proxy for labor use in farmland. Per capita annual income (C) of a rural population connects agricultural production to the local economy. As rural people began participating gradually in non-agricultural activities, a question became whether the local farmers would invest their income in increased agricultural production by purchasing commercial inputs. If they did so, the relationship between their income and farmland area should be positive; otherwise, if they had enough access to other business activities, there would 
be less desire for agricultural expansion, in which case the relationship between rural income and farmland expansion could be negative.

Agricultural machinery power $(T)$ is a main indicator of the technological sophistication of agricultural production. The agricultural machinery power of each county is documented in Heilongjiang's statistical yearbooks. A concern is whether this variable is representative of local agricultural technology adoption, because technological improvement could be embedded in various inputs, such as better seeds, more fertilizer and pesticide use, and adoption of more effective methods of cultivation. Unfortunately, we could not find any statistics to capture these phenomena. Of course, even if machinery is an appropriate indicator for farming technology, a large machinery use does not guarantee a high technological efficiency. Data on theprice index of agricultural products (Ap) were collected from Heilongjiang Price Annals (volume 42) for the period of 1976-1985 (Compilation Committee of Heilongjiang Annals, 1993) and Heilongjiang Statistical Yearbook thereafter (Heilongjiang Statistical Bureau, 1986-2014). Agricultural product prices increased graduallyafter the dual-track pricing system was introduced in 1985 (Qian, 2000); prices reached their peak during 1996-1997, partly caused by the high levels of countrywide inflation in 1994 (Wang, 2008).

Variables used in the wetland equationData for irrigation area (I) were taken from Heilongjiang Statistics Bureau (2009). Precipitation (Pr) and temperature (Te) were the mean values of inverse distance weighting over the 32 meteorological stations in Heilongjiang (Bartier and Keller, 1996; Childs, 2004), and the information of the 32 stations was acquired from the website of the China Meteorological Data Sharing Service System (National Meteorological Information Center, 2009). We argue that in addition to the human drivers, natural factors like decreased precipitation and warming temperatures have also contributed to wetland loss. Indeed, 
Yan et al. (2002) observed that in the Sanjiang Plain, the annual average temperature rose from $1.2^{\circ} \mathrm{C}$ in 1955 to $2.3^{\circ} \mathrm{C}$ in 1999 . Zhou et al. (2009) also confirmed the decreasing precipitation trend with data from the Jiansanjiang Weather Station during 1957 to 2000.

\section{Empirical findings}

Our initial scrutiny indicated that the mean value of farmland is indeed correlated with the error term in a single equation regression. As such, ignoring the issue that farmland expansion might not truly be exogenous and thus taking it as independent variables could cause biased estimation(Mundlak, 1978). Below, we present the estimated results of the two alternative modelingsystems.

\subsection{Results of the two dominant classes of land use}

As a preliminary step, it is necessary to validate the selected instruments and the goodness of fit of first-stage regression.Table 2 reports the testing results in terms of under-identification, weak identification, and weak-instrument-robust inference. Four diagnostic tests were conducted in the second-stage: endogeneity test, under-identification test, weak identification test, and overidentification test. The statistics for the under-identification and weak identification tests are the same as those done in the first stage, while the endogeneity and over-identification tests are specific to the second stage (see Appendixfor more detail).

$<$ Insert Table 2 here $>$

When all instruments were included, they passed all the tests except the Hansen $J$ test (Pitt, 2011), which rejected the assumption that "all the excluded instruments are valid" (see Appendix), casting doubt over the validity of this instrument combination. To ensure that only 
the exogenous instrumental variables are included, we took a further step to try different instrument combinations and recorded the corresponding test statistics (see Table 2). However, all of the over-identification test results still could not eliminate the doubt over the validity of these instruments. This validation process thus continued until we found that the variable builtup land fits well as an instrument. Our endogeneity test rejected the null hypothesis - no endogeneity, while the testing power of under-identification did not lose much by keeping builtup land as the only instrument in the model. These insights lent us confidence in the choice of built-up land as a good instrument for farmland and, therefore, we dropped all the other instrument candidates.

Table 3 reports our results for two dominant land-use classes, with the endogenous variable farmland being instrumented by built-up land. Models 1-2 were estimated using different fixed effects, or FE, estimators (see notes below the table for more detail about the alternative specifications). Also, it is routine to require that all the regression models be at least robust to heteroskedasticities (Wooldridge, 1996). From Table 3, we see that all the FE models report very close coefficient estimates and standard errors. In these estimations, one unit of forestland loss is associated with 1.51 units of farmland expansion. And the policy dummy for the NFPP has a strong, positive effect on forestland, with a coefficient of 56.31. Forestland is correlated with slowly rising timber prices, but the relationship is notstrong. Meanwhile, the gross output value of forestry has little effects on forestland changes.

$<$ Insert Table 3 here $>$

The random effects (RE) models (3 and 4 in Table 3) are meant to offer complimentary perspectives for the system. Recall that the two time-invariant variables - the mean distance to nearby cities (and timber markets) and the number of forest farms located within a county-were 
dropped in the FE analysis. The highly significant coefficients of "Meandist" suggest that forest farms located farther away from timber markets and large cities tend to suffer less deforestation. Also, with more forest farms clustered in same county, the forestland tends to be better protected. These additional findings are useful for a more nuanced understanding of the driving forces of deforestation and their interaction.

Generally speaking, though, the differences between the RE results and the FE ones are fairly small. The coefficient magnitudes and significances of most variables, like NFPP, forestryoutput, and timber price, as well as population, are very similar. Compared to the FE results, it is obvious that the overall correlation between farmland and forestland is smaller in magnitude in the RE regressions. For example, the estimatedFE coefficient of farmland is -1.51, while the coefficient falls in the range from -1.48 to -1.22 in the RE versions.

\subsection{Results of the system of three equations}

Here, we began with a pre-estimation validation ofthe three separate equationsand our testing results are presented in Table 4. First, we verified the relationship between equations. The correlation coefficient between the error terms of the forestland equation and the farmland equation is 0.50 ; the same coefficient between the forestland and wetland equations is 0.04 and that between the farmland and wetland equations is -0.61 . Then, we employed the BreuschPagan LM Diagonal Covariance Matrix Test to discern whether the OLS estimate is appropriate (Shehata, 2014). The testing outcomes rejected the null with a $P$-Value close to zero (Lagrange Multiplier Test $=184.68)$, in favor of the alternative 3SLS.Taken together, these results confirm the logic of our approach—-treating the three interlinked classes of land use as an integrated system. 


\section{<Insert Table 4 here $>$}

The second column of Table 4 lists the expected signs of the variables listed in the first column and the last three columns report the estimated results. The coefficient estimates of the forestland equation are generally consistent with those of the 2SLS model, in which farmland has a strong and negative correlation with forestland (-1.37), and area of wetland is also negatively correlated $(-0.49)$ with area of forestland due to their mutual substitutability in the process of farmland expansion. The negative coefficient of population shows that increasing population could have put pressure on forest resource extraction, leading to more forestland loss. On the other hand, the NFPP is positively correlated with forestland change, indicating that the NFPP has protected the natural forests from further deterioration. While the positive effect of timber price seems counterintuitive, it is likely that forestland can expand, partially in response to higher timber prices over the long run.

In the farmland equation,the price index of agricultural productswas excluded because it had little effect on farmland change. Included are per capita annual net income of rural population, number of agricultural population, and total agricultural machinery power to capture the effects of changed inputs and outputs on farmland.The significantly positive coefficient $(0.10)$ of farmers' net income indicates that it is highly correlated with agricultural expansion.The coefficient of agricultural machinery is positively correlated with farmland expansion, revealing that the use of machinery results in farmland expansion at the extensive margin. However, as the region has been characterized by falling fertility and high rates of rural to urban migration, the rural population is negatively correlated with agricultural expansion.

In the wetland equation, as expected, farmland expansion is strongly negatively correlated with wetland loss, with a coefficient of -0.64 . The relationship between wetland and 
forestland is once again substitutional. The significantly negative coefficient (-3.15) of irrigation area confirms the view that wetland loss is strongly related to the change in local cropping pattern (from dryland crops to irrigated crops). In addition, the warming climate also contributed to wetland loss over the past 37 years(-1.97).

\section{Discussion and conclusions}

The motivation of this study was to explore the driving forces of forest dynamics in northeast China in a more systematic way. One of the important questions was whether or not the large NFPP has been effective in protecting the natural forests. Our literature review quickly revealed that studies of the driving forces of forestland change in general and the effectiveness and impact of the NFPP in particular were limited, and they tended to focus on the short-term outcomes. Few had consideredthe NFPP in an adequate historical context and examined the regional depletion and possible recovery of natural forests, and even fewer had investigated the major factors affecting the resource dynamics from a more holistic view. These observations ledus toconsider the NFPP from the perspective of LULCC over a longer time span.

Based on our analysis of the land-use changes derived from satellite images, we first constructed an interactive system of the two classes of land use-forestland and farmland, assuming that farmland could be endogenous in explaining the deforestation process. Then, a series of formal statistical tests was conducted to select appropriate instruments among multiple combinations of candidate variables that were thought to be relevant to agricultural development. It was found that built-up land, which increased along with farmland expansion but did not have a direct relationship with forestland, was the only satisfactory instrument. Meanwhile, tests also demonstrated that the finite sample bias of IV analysis is smaller than that of OLS. The IV 
results provided strong evidence of endogeneity of land use; thus, we went a step further by including another class of land use-wetland—in a system of three equations, with forestlandfarmland-wetland being jointly determined. The interactive relationships of the three classes of land use rendered this system to be a simultaneous equations model. Moreover, different estimation strategies were adopted to assess the performance of the regression methods as well as the estimated results. Importantly, the alternative models have corroborated the consistency of our empirical results, lending confidence over their robustness and reliability.

Forestland change is a process stemming from the complex interactions among many factors. The basic proximate cause of deforestation is agricultural expansion; meanwhile, wetland change serves as a substitute of forestland change in the face of farmland expansion(Shi et al. 2016). These two proximate causes in turn are mediated by certain underlying determinants, which include effect of the NFPP, population growth, timber prices, wage rates, and technological and climate changes. We also considered some other perceived "underlying” factors, like GDP and regional altitude. As they were only slightly associated with various categories of land use, we dropped them from our analysis. Our results show that deforestation has a strong and negative correlation with farmland expansion, and wetland change has a substitutive effect with forestland—reduction of wetland tends to save some forestland from loss, and vice versa. Our results also identify a robust linkage between government policy and forestland change- -theNFPP has indeed played a significantly positive role in protecting local forests. There is a significant correlation between population growth and deforestation. As other income opportunities for local farmers were limited, families continued clearing land to expand farming and increase their revenues. This is consistent with a bulk of the evidence reported in the literature (Angelsen and Kaimowitz, 1999; Carr et al., 2005; Geist and Lambin, 2001). It is also 
found that forests located closer to a county seat and/or a large timber market tend to have a higher probability of deforestation; similarly, counties with more forest farms and thus a greater presence of forestry administration in their jurisdictions tend to have a lower risk of forestland loss.

The estimated coefficients in the farmland equationof the 2SLS model are also interesting. Size of agricultural population is negatively associated with farmland expansion. Population growth is widely recognized as a trigger of LULCC (Angelsen, 1999; Carr et al., 2005; Cropper et al., 1997),that is, limited farmland per capita can lead farmers to clear forests. However, as stated before, rural population in our study region has declined. Additionally, along with the increasing use of machinery, the technology progress in farming changed the relative scarcities of inputs, which could have possibly reduced the pressuresthat population growth placed on agriculture. The positive association between the agricultural machinery power and farmland area confirms that ruralpopulation or labor is not a constraint for local agricultural production. On the other hand, local farmers' revenue increases and machinery purchases have a strong influence on farmer's land allocation decisions.

Moreover, the correlation coefficients of wetland change with farmland expansion and forestland loss withinthe SEM confirm the importance of considering substitution effects between forestland and wetland in analyzing the driving forces of forestland change.The warming climate has steadily contributed to wetland loss over the past decades, and wetland area also fluctuated due to the floodplain variation according to different amounts of precipitation. Above all, irrigation area increase played a dominant role in wetland loss. The negative coefficient of irrigation area validates the view that wetland loss is strongly related to the change in local cropping pattern, from dryland crops to paddy rice. 
Some of the estimated coefficients seem counter-intuitive. For instance, timber price is positively, but insignificantly, correlated with forestland changes. It is generally viewed that timber price increases would lead to more logging and thus deforestation at least in the short run, so that the impact should be significantly negative. Our conjecture is that under government market control, timber prices were depressed and thus did not play much of a role in the study region (Yin et al., 2003; Zhang, 2000, 2001). A closer examination shows that the timber price index went up sharply after 2000, exactly when the NFPP was initiated; before that time, it fluctuated within a relatively small range and did not demonstrate any trend as deforestation did. This implies that timber price had little effect on local farmers' decisions over timber harvesting or forestland clearing. It is conceivable that the long-run price effect may be positive if the incentive structure for reforestation and forest management can be improved persistently.

Overall, the alternative models and estimation strategies have corroborated the consistency of our empirical results, which is encouraging and thus should mitigate the concerns with our land-use data interpolation as well as the smallsize of our sample. At the same time, we must admit that our dataset does have limitations. First, as noted, we were unable to capture any of the potential spatial correlation and we were unable to adequately capture the temporal correlation given the limited cross-sections and time-series. Second, the small sample size made our estimated results sensitive to the modeling framework used and assumptions made. Further, we had to ignore potential time lags between dependent and independent variables due to the limited degree of freedom. So, caution is warranted in interpreting the estimated results.It is hoped that future research will be able to overcome these problems. Accumulating longer timeseries and larger cross-sectional data will be a fundamental undertaking in order to accommodate more advance econometric tools and frameworks to derive more robust empirical results. Also, if 
possible, observationswith higher quality and reliability should be incorporated into the dataset. Moreover, data for other relevant variables, such as changes in the ecological conditions induced by implementing the NFPP, should be collected or updated.

Acknowledgments: This research was partially supported by the U.S. National Science Foundation, and Center for Advanced Studies of International Development, Asian Studies Center, and AgBioResearch of Michigan State University. We are grateful to Jiaguo Qi and many other faculties, students, and visiting scholars at the Center for Global Change and Earth Observations of Michigan State University for their valuable comments and suggestions. We also appreciate the assistance during field trips from Li Jia of Northeast Agriculture University and Yukun Cao of Northeast Forestry University, China. Any remaining errors are our own.

Author Contributions: Runsheng Yin conceived and designed the research; Miaoying Shi analyzed the data, Hongdi Lv helped the final revision.

Conflicts of Interest: The authors declare no conflict of interest. The funding sponsors had no role in the design of the study; in the collection, analyses, or interpretation of data; in the writing of the manuscript, and in the decision to publish the results. 


\section{References}

Anderson, T. W., \& Rubin, H. (1949). Estimation of the parameters of a single equation in a complete system of stochastic equations. The Annals of Mathematical Statistics, 46-63.

Andrews, D., \& Stock, J. H. (2005). Inference with weak instruments: National Bureau of Economic Research Cambridge, Mass., USA.

Angelsen, A. (1999). Agricultural expansion and deforestation: modelling the impact of population, market forces and property rights. Journal of Development Economics, 58(1), 185-218.

Angelsen, A., \& Kaimowitz, D. (1999). Rethinking the Causes of Deforestation: Lessons from Economic Models. The World Bank Research Observer, 14(1), 73-98.

Angelsen, A., Shitindi, E. F. K., \& Aarrestad, J. (1999). Why do farmers expand their land into forests? Theories and evidence from Tanzania. Environment and Development Economics, 4(03), 313-331.

Angrist, J. D., Imbens, G. W., \& Rubin, D. B. (1996). Identification of causal effects using instrumental variables. Journal of the American Statistical Association, 91(434), 444-455.

Angrist, J. D., \& Krueger, A. B. (2001). Instrumental Variables And The Search For Identification: From Supply And Demand To Natural Experiments. Journal of Economic Perspectives, 15(4), 69-85.

Asner, G. P., Broadbent, E. N., Oliveira, P. J., Keller, M., Knapp, D. E., \& Silva, J. N. (2006). Condition and fate of logged forests in the Brazilian Amazon. Proceedings of the National Academy of Sciences, 103(34), 12947-12950.

Asner, G. P., Knapp, D. E., Broadbent, E. N., Oliveira, P. J., Keller, M., \& Silva, J. N. (2005). Selective logging in the Brazilian Amazon. Science, 310(5747), 480-482.

Baltagi, B. H. (2006). An Alternative Derivation of Mundlak's Fixed Effects Results Using System Estimation. Econometric Theory, 22(6), 1191-1194.

Baltagi, B. H., \& Giles, M. D. (1998). Panel data methods. Statistics Textbooks and Monographs, 155, 291-324.

Baltagi, B. H., \& Liu, L. (2009). A note on the application of EC2SLS and EC3SLS estimators in panel data models. Statistics \& Probability Letters, 79(20), 2189-2192.

Bartier, P. M., \& Keller, C. P. (1996). Multivariate interpolation to incorporate thematic surface data using inverse distance weighting (IDW). Computers \& Geosciences, 22(7), 795-799.

Baum, C. F., Schaffer, M. E., \& Stillman, S. (2007a). Enhanced routines for instrumental variables/GMM estimation and testing. Stata Journal, 7(4), 465-506.

Baum, C. F., Schaffer, M. E., \& Stillman, S. (2007b). ivreg2: Stata module for extended instrumental variables/2SLS, GMM and AC/HAC, LIML and k-class regression.

Bekker, P. A., \& Ploeg, J. (2005). Instrumental variable estimation based on grouped data. Statistica Neerlandica, 59(3), 239-267.

Brownstone, D., Golob, T. F., \& Kazimi, C. (Producer). (2002). Modelling non-ignorable attrition and measurement error in panel surveys: an application to travel demand modeling. Earlier Faculty Research. Retrieved from https://escholarship.org/uc/item/262891mq

Burgess, J. C. (1993). Timber production, timber trade and tropical deforestation. Ambio, 22(2/3), 136-143.

Cameron, A. C., \& Trivedi, P. K. (2009). Microeconometrics using stata (Vol. 5): Stata Press College Station, TX. 
Carr, D., Suter, L., \& Barbieri, A. (2005). Population dynamics and tropical deforestation: State of the debate and conceptual challenges. Population \& Environment, 27(1), 89-113.

Chenhall, R. H., \& Moers, F. (2007). The issue of endogeneity within theory-based, quantitative management accounting research. European Accounting Review, 16(1), 173-196.

Chernozhukov, V., \& Hansen, C. (2008). The reduced form: A simple approach to inference with weak instruments. Economics Letters, 100(1), 68-71.

Childs, C. (2004). Interpolating surfaces in ArcGIS spatial analyst. ArcUser, July-September, 3235.

Chomitz, K. M., \& Gray, D. A. (1996). Roads, Land Use, and Deforestation: A Spatial Model Applied to Belize. The World Bank Economic Review, 10(3), 487-512.

Compilation Committee of Heilongjiang Annals. (1993). Heilongjiang Price Annals (Vol. 42). Harbin: Helongjiang People's Press.

Cornwell, C., Schmidt, P., \& Wyhowski, D. (1992). Simultaneous equations and panel data. Journal of Econometrics, 51(1-2), 151-181. doi:http://dx.doi.org/10.1016/03044076(92)90033-N

Cragg, J. G., \& Donald, S. G. (1993). Testing identifiability and specification in instrumental variable models. Econometric Theory, 9(02), 222-240.

Cropper, M., Griffiths, C., \& Mani, M. (1997). Roads, population pressures, and deforestation in Thailand, 1976-89. World Bank Policy Research Working Paper(1726).

De Janvry, A., Fafchamps, M., \& Sadoulet, E. (1991). Peasant household behaviour with missing markets: some paradoxes explained. The Economic Journal, 101(409), 1400-1417.

Epple, D. (1987). Hedonic prices and implicit markets: estimating demand and supply functions for differentiated products. The Journal of Political Economy, 95(1), 59-80.

Färe, R., Grosskopf, S., Norris, M., \& Zhang, Z. (1994). Productivity growth, technical progress, and efficiency change in industrialized countries. The American Economic Review, 84(1), 66-83.

Fingleton, B., \& Gallo, J. L. (2007). Finite Sample Properties of Estimators of Spatial Models with Autoregressive, or Moving Average, Disturbances and System Feedback. Annals of Economics and Statistics(87/88), 39-62. doi:10.2307/27650041

Geist, H. J., \& Lambin, E. F. (2001). What drives tropical deforestation? A meta-analysis of proximate and underlying causes of defores-tation based on subnational scale case study evidence. Retrieved from University of Louvain, Louvain-la-Neuve:

Geist, H. J., \& Lambin, E. F. (2002). Proximate Causes and Underlying Driving Forces of Tropical Deforestation. BioScience, 52(2), 143-150. doi:10.1641/00063568(2002)052[0143:pcaudf]2.0.co;2

Grossman, G. M., \& Helpman, E. (1993). Endogenous innovation in the theory of growth. Journal of Economic Perspectives, 8(1), 23-44.

Hausman, J. A., Newey, W. K., \& Woutersen, T. M. (2007). IV Estimation with Heteroskedasticity and Many Instruments. Retrieved from http://economics.mit.edu/files/1544

Hausman, J. A., \& Taylor, W. E. (1981). Panel Data and Unobservable Individual Effects. Econometrica, 49(6), 1377-1398.

Hayashi, F. (2000). Econometrics Princeton University Press: Princeton.

Heilongjiang Statistical Bureau. (1986-2014). Heilongjiang Statistical Yearbook (1986-2014). Beijing: China Statistics Press. 
Heilongjiang Statistics Bureau. (2009). Sixty Years of Heilongjiang. Beijing: China Statistics Press.

Herbert, A. J., \& Arild, A. (2009). The paradox of household resource endowment and land productivity in Uganda. Paper presented at the Agricultural Economists Conference, Beijing. http://ageconsearch.umn.edu/handle/51691

Huang, W., Deng, X., Lin, Y., \& Jiang, Q. (2010). An Econometric Analysis of Causes of Forestry Area Changes in Northeast China. Procedia Environmental Sciences, 2(2), 557565.

Irwin, E. G., \& Geoghegan, J. (2001). Theory, data, methods: developing spatially explicit economic models of land use change. Agriculture, Ecosystems \& Environment, 85(1-3), 7-24. doi:10.1016/s0167-8809(01)00200-6

Jiang, L., Yan, P., Wang, P., Shi, J., Yang, X., Dong, J., . . Nan, R. (2006). Influence of climatic factors on safety of rice production in Heilongjiang Province. Journal of Natural Disasters, 15(3), 46-51.

Jiang, X., Gong, P., Bostedt, G., \& Xu, J. (2014). Impacts of policy measures on the development of state-owned forests in northeast China: theoretical results and empirical evidence. Environment and Development Economics, 19(01), 74-91.

Jöreskog, K. G., \& Sörbom, D. (1986). LISREL VI: Analysis of linear structural relationships by maximum likelihood, instrumental variables, and least squares methods. Ann Arbor: Scientific Software.

Kaimowitz, D., \& Angelsen, A. (1998). Economic models of tropical deforestation: a review. Jakarta: Centre for International Forestry Research.

Kalirajan, K. P., Obwona, M. B., \& Zhao, S. (1996). A decomposition of total factor productivity growth: the case of Chinese agricultural growth before and after reforms. American Journal of Agricultural Economics, 78(2), 331-338.

Key, N., \& Runsten, D. (1999). Contract farming, smallholders, and rural development in Latin America: the organization of agroprocessing firms and the scale of outgrower production. World Development, 27(2), 381-401.

Kleibergen, F., \& Paap, R. (2006). Generalized reduced rank tests using the singular value decomposition. Journal of Econometrics, 133(1), 97-126.

Lambin, E. F., Turner, B. L., Geist, H. J., Agbola, S. B., Angelsen, A., Bruce, J. W., . . Folke, C. (2001). The causes of land-use and land-cover change: moving beyond the myths. Global Environmental Change, 11(4), 261-269.

Louviere, J., Train, K., Ben-Akiva, M., Bhat, C., Brownstone, D., Cameron, T. A., .. . Greene, W. (2005). Recent progress on endogeneity in choice modeling. Marketing Letters, 16(34), 255-265.

Mainardi, S. (1998). An economitric analysis of factors affecting tropical and subtropical deforestation. Agrekon, 37(1), 23-65.

Mertens, B., \& Lambin, E. F. (2000). Land-cover-change trajectories in southern Cameroon. Annals of the Association of American Geographers, 90(3), 467-494.

MOF. (1997). China Forestry Yearbook 1996. Beijing (in Chinese): China Forestry Publishing House (Ministry of Forestry).

Moreira, M. J. (2003). A conditional likelihood ratio test for structural models. Econometrica, 71(4), 1027-1048. 
Mullan, K., Kontoleon, A., Swanson, T., \& Zhang, S. (2009). An evaluation of the impact of the Natural Forest Protection Programme on Rural Household Livelihoods An Integrated Assessment of China's Ecological Restoration Programs (pp. 175-199): Springer.

Mundlak, Y. (1978). On the pooling of time series and cross section data. Econometrica: Journal of the Econometric Society, 46(1), 69-85.

Murray, M. P. (2006). Avoiding invalid instruments and coping with weak instruments. The journal of economic perspectives, 20(4), 111-132.

National Meteorological Information Center. (2009). China Meteorological Data Sharing Service System. http://www.cma.gov.cn/2011qxfw/2011qsjgx/

NFPP Management Center. (2011). Authoritative interpretations for the second phase policies of natural forest protection project (In Chinese). Retrieved from http://www.forestry.gov.cn/ZhuantiAction.do?dispatch=content\&id=484664\&name=trlb hgc

Nickell, S. (1981). Biases in Dynamic Models with Fixed Effects. Econometrica, 49(6), 14171426.

Pfaff, A. S. (1999). What drives deforestation in the Brazilian Amazon?: evidence from satellite and socioeconomic data. Journal of Environmental Economics and Management, 37(1), 26-43.

Pitt, M. M. (2011). Overidentification tests and causality: a second response to Roodman and Morduch. draft. Brown University. Retrieved from http://www. pstc. brown. edu/ mp/papers/Overidentification. pdf

Qian, Y. (2000). The process of China's market transition (1978-1998): The evolutionary, historical, and comparative perspectives. Journal of Institutional and Theoretical Economics (JITE), 156(1), 151-171.

Rudel, T., \& Roper, J. (1997). The paths to rain forest destruction: Crossnational patterns of tropical deforestation, 1975-1990. World Development, 25(1), 53-65.

Sanderson, E., \& Windmeijer, F. (2013). A weak instrument F-test in linear IV models with multiple endogenous variables. Retrieved from http://www.econstor.eu/handle/10419/97410

Schaffer, M. E. (2012). xtivreg2: Stata module to perform extended IV/2SLS, GMM and AC/HAC, LIML and k-class regression for panel data models. Statistical Software Components.

Semykina, A., \& Wooldridge, J. M. (2010). Estimating panel data models in the presence of endogeneity and selection. Journal of Econometrics, 157(2), 375-380.

SFA. (2005). Statistics on the national forest resources (the 6th National Forest Inventory 19992003). Beijing (in Chinese): State Forestry Administration.

Shehata, E. A. E. (2014). LMCOVREG3: stata module to compute Breusch-Pagan Lagrange multiplier diagonal covariance matrix test after (3SLS-SURE) regressions. Statistical Software Components.

Shen, Y.Q., Liao, X.C., Yin, R.S., 2006. Measuring the Socioeconomic Impacts of China's Natural Forest Protection Program. Environment and Development Economics 11(6): 769-788.

Shi, M. (2015). Forest cover change in Northeast China during the period of 1977-2007 and its driving forces. East Lansing, Michigan State University (dissertations - Gradworks).

Shi, M., Qi, J., Yin, R., (2016). Has China’s Natural Forest Protection Program Protected Forests? Heilongjiang's Experience. Forests (in press). 
Song, K., Liu, D., Wang, Z., Zhang, B., Jin, C., Li, F., \& Liu, H. (2008). Land use change in Sanjiang Plain and its driving forces analysis since 1954. Acta Geographica Sinica (Chinese Edition), 63(1), 81-93.

Staiger, D. O., \& Stock, J. H. (1994). Instrumental variables regression with weak instruments. Econometrica, 65(3), 557-586.

Stock, J. H., \& Wright, J. H. (2000). GMM with weak identification. Econometrica, 68(5), 10551096.

Stock, J. H., Wright, J. H., \& Yogo, M. (2002). A survey of weak instruments and weak identification in generalized method of moments. Journal of Business \& Economic Statistics, 20(4), 518-529.

Stock, J. H., \& Yogo, M. (2005). Testing for weak instruments in linear IV regression. Identification and inference for econometric models: Essays in honor of Thomas Rothenberg.

Sun, Q., Zhang, S., Zhang, J., \& Yang, C. (2010). Current Situation of Rice Production in Northeast of China and Countermeasures. North Rice, 2, 2-32.

Turner, B. L., Lambin, E. F., \& Reenberg, A. (2008). Land Change Science Special Feature: The emergence of land change science for global environmental change and sustainability. Proceedings of the National Academy of Sciences of the United States of America, 105(7), 2751-2751.

Verburg, P., Schot, P., Dijst, M., \& Veldkamp, A. (2004). Land use change modelling: current practice and research priorities. GeoJournal, 61(4), 309-324. doi:10.1007/s10708-0044946-y

Wang, T. (2008). Effective measurements to tackle the problem of rising price. Retrieved from http://paper.people.com.cn/rmlt/html/2008-05/16/content_48573240.htm

Windmeijer, F. (2005). A finite sample correction for the variance of linear efficient two-step GMM estimators. Journal of Econometrics, 126(1), 25-51. doi:http://dx.doi.org/10.1016/j.jeconom.2004.02.005

Wooldridge, J. M. (1996). Estimating systems of equations with different instruments for different equations. Journal of Econometrics, 74(2), 387-405. doi:http://dx.doi.org/10.1016/0304-4076(95)01762-3

Wooldridge, J. M. (2002). Econometric Analysis of Cross Section and Panel Data. Cambridge: The MIT Press.

Xu, J., Tao, R., \& Amacher, G. S. (2004). An empirical analysis of China's state-owned forests. Forest Policy and Economics, 6(3), 379-390.

Xu, J., Yin, R., Li, Z., \& Liu, C. (2005). China's ecological rehabilitation: the unprecedented efforts and dramatic impacts of reforestation and slope protection in western China. Ecological Economics, 57(4), 595-607.

Xu, J., Yin, R., Li, Z., \& Liu, C. (2006). China's ecological rehabilitation: Unprecedented efforts, dramatic impacts, and requisite policies. Ecological Economics, 57(4), 595-607. doi:10.1016/j.ecolecon.2005.05.008

Yan, M., Deng, W., \& Chen, P. (2002). Climate change in the Sanjiang Plain disturbed by largescale reclamation. Journal of Geographical Sciences, 12(4), 405-412.

Yin, R. (1998). Forestry and the environment in China: the current situation and strategic choices. World Development, 26(12), 2153-2167.

Yin, R., \& Newman, D. H. (1996). The effect of catastrophic risk on forest investment decisions. Journal of Environmental Economics and Management, 31(2), 186-197. 
Yin, R., \& Xiang, Q. (2010). An integrative approach to modeling land-use changes: multiple facets of agriculture in the Upper Yangtze basin. Sustainability Science, 5(1), 9-18.

Yin, R., Xu, J., \& Li, Z. (2003). Building institutions for markets: Experiences and lessons from China's rural forest sector. Environment, Development and Sustainability, 5(3-4), 333351.

Yin, R., Xu, J., Li, Z., \& Liu, C. (2005). China's ecological rehabilitation: the unprecedented efforts and dramatic impacts of reforestation and slope protection in western China. China Environment Series, 6, 17-32.

Yin, R., \& Yin, G. (2009). China's Ecological Restoration Programs: Initiation, Implementation, and Challenges An Integrated Assessment of China's Ecological Restoration Programs (pp. 1-19): Springer Netherlands.

Yin, R., \& Yin, G. (2010). China's primary programs of terrestrial ecosystem restoration: initiation, implementation, and challenges. Environmental Management, 45(3), 429-441.

Yu, D., Zhou, L., Zhou, W., Ding, H., Wang, Q., Wang, Y., . . . Dai, L. (2011). Forest management in Northeast China: history, problems, and challenges. Environmental Management, 48(6), 1122-1135.

Zhang, J., Ma, K., \& Fu, B. (2010). Wetland loss under the impact of agricultural development in the Sanjiang Plain, NE China. Environmental Monitoring and Assessment, 166(1-4), 139148.

Zhang, K., Hori, Y., Zhou, S., Michinaka, T., Hirano, Y., \& Tachibana, S. (2011). Impact of Natural Forest Protection Program policies on forests in northeastern China. Forestry Studies in China, 13(3), 231-238.

Zhang, P., Shao, G., Zhao, G., Le Master, D. C., Parker, G. R., Dunning Jr, J. B., \& Li, Q. (2000). China's forest policy for the 21st century. Science, 288(5474), 2135-2136.

Zhang, S., Na, X., Kong, B., Wang, Z., Jiang, H., Yu, H., . . . Dale, P. (2009). Identifying wetland change in China's Sanjiang Plain using remote sensing. Wetlands, 29(1), 302313. doi:10.1672/08-04.1

Zhang, Y. (2000). Costs of Plans vs Costs of Markets: Reforms in China's State - owned Forest Management. Development Policy Review, 18(3), 285-306.

Zhang, Y. (2001). Deforestation and forest transition: theory and evidence in China. In M. Palo \& H. Vanhanen (Eds.), World forests from deforestation to transition? (Vol. 2, pp. 41-65). Netherlands: Springer.

Zhou, D., Gong, H., Wang, Y., Khan, S., \& Zhao, K. (2009). Driving forces for the marsh wetland degradation in the Honghe National Nature Reserve in Sanjiang Plain, Northeast China. Environmental Modeling \& Assessment, 14(1), 101-111. 


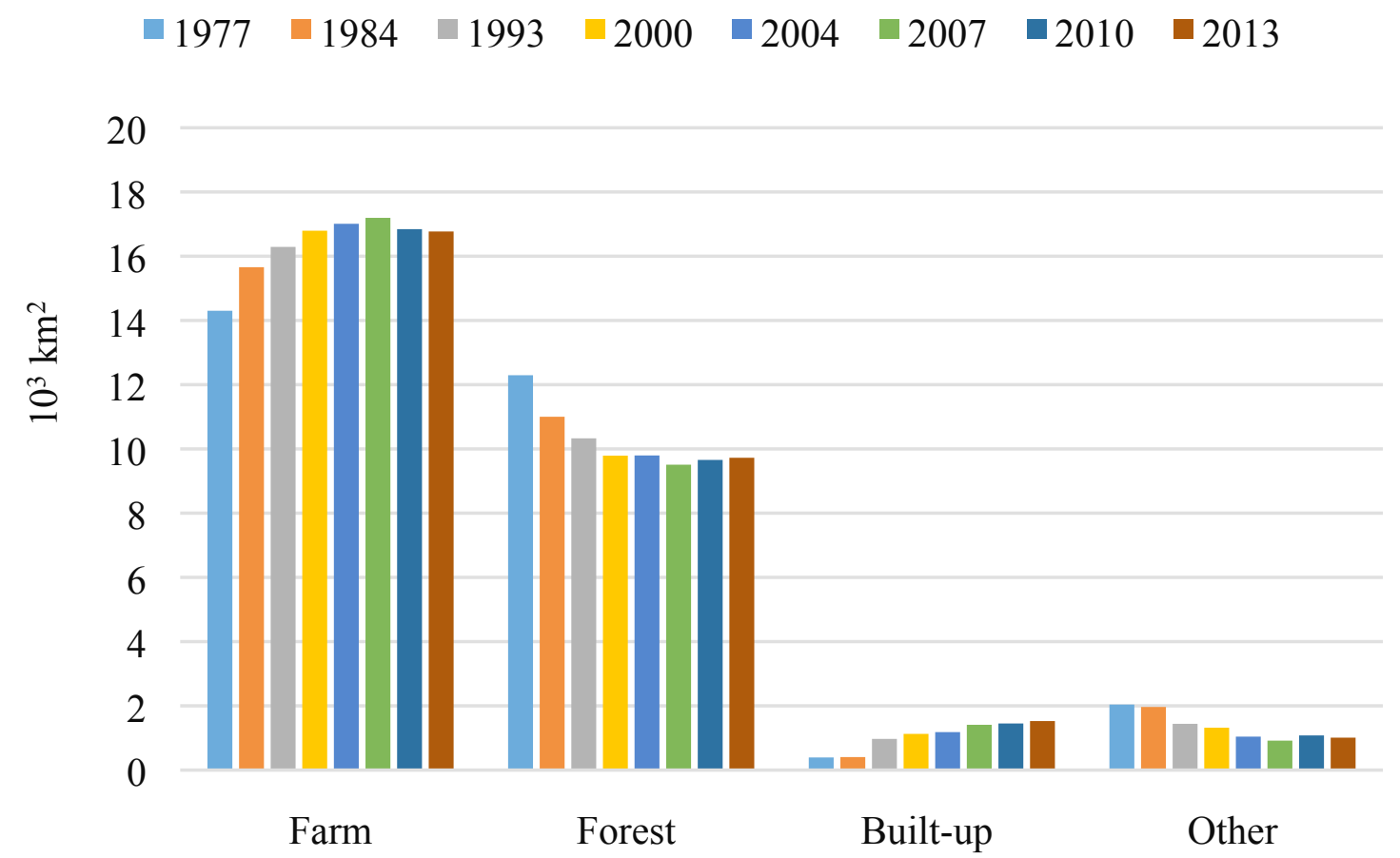

Figure 1. Land-use changes in the study area during 1977-2013 (Shi et al. 2016)

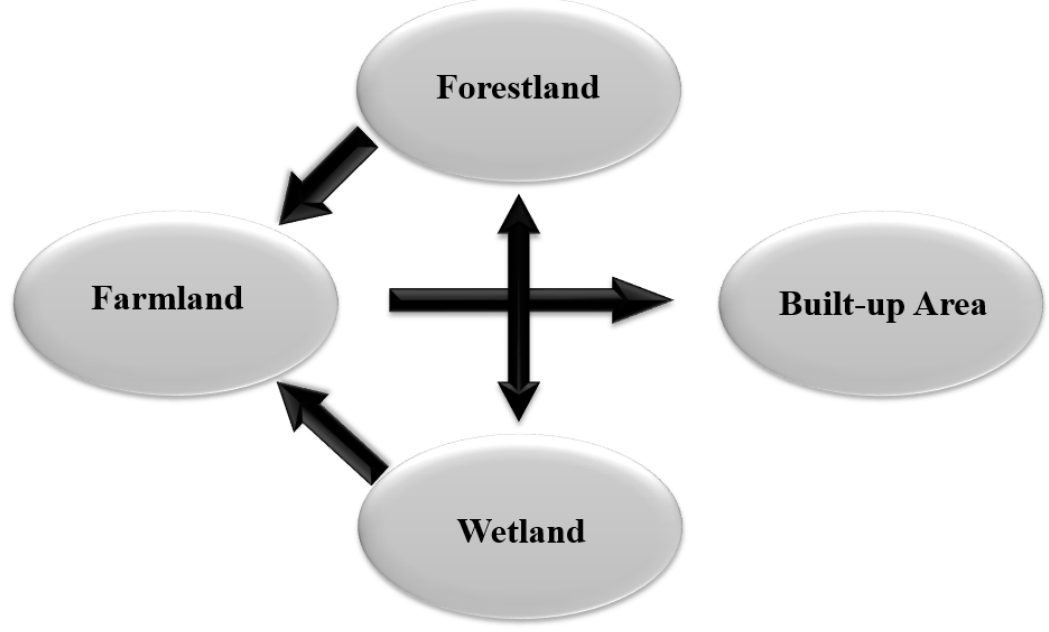

Figure 2. Major land-use conversion directions during 1977-2013 (adapted from Shi et al. [2016]) 
Table 1. Data summary and variable description

\begin{tabular}{|c|c|c|c|c|c|c|}
\hline Variable Definition & Abbr. & Unit & Mean & Std & Min & Max \\
\hline Forest Area & $F t$ & $\mathbf{K m}^{2}$ & 1194.52 & 901.92 & 5.13 & 2622.70 \\
\hline Timber Price Index & $T p$ & $1976=100$ & 88.90 & 23.46 & 54.50 & 161.60 \\
\hline Gross Value of Forestry Outputs & $O$ & 1,000 Yuan & 4538.87 & 5165.00 & 164.99 & 33424.47 \\
\hline Distance to Nearby Markets & $D$ & $\mathrm{Km}$ & 26.10 & 9.57 & 15.96 & 46.56 \\
\hline Number of Forest Farms & $N f$ & 1 & 6.38 & 4.04 & 1.00 & 13.00 \\
\hline Natural Forest Protection Program & $N$ & 0 before $2000 ; 1$ otherwise & 0.30 & 0.46 & 0.00 & 1.00 \\
\hline Total Population & $P$ & 1,000 & 305.76 & 99.79 & 104.00 & 527.50 \\
\hline Farm Area & $F m$ & $\mathbf{K m}^{2}$ & 1773.47 & 799.59 & 206.25 & 2876.01 \\
\hline Agricultural Population & $L$ & 1,000 & 199.11 & 71.51 & 53.03 & 342 \\
\hline Rural Per Capita Annual Net Income & $C$ & Yuan & 312.06 & 192.39 & 36.04 & 920.31 \\
\hline Agricultural Machinery Power & $T$ & $1000 \mathrm{kWh}$ & 137.73 & 68.08 & 27.21 & 417.80 \\
\hline Price Index of Agricultural Products & $A p$ & $1976=100$ & 344.00 & 170.34 & 100.00 & 578.04 \\
\hline Wetland & $W t$ & $\mathbf{K m}^{2}$ & 173.59 & 231.38 & 2.04 & 1033.88 \\
\hline Irrigation Area & $I$ & $\mathrm{Km}^{2}$ & 131.26 & 70.33 & 60.50 & 295.00 \\
\hline Average Annual Precipitation & $\operatorname{Pr}$ & $\mathrm{mm}$ & 524.01 & 70.85 & 383.49 & 657.59 \\
\hline Average Annual Temperature & $T e$ & $0.1^{\circ} \mathrm{C}$ & 30.34 & 7.44 & 17.06 & 46.50 \\
\hline
\end{tabular}

Note: Yuan is the unit of Chinese currency, $\mathrm{kWh}$ is short for kilowatt hour, and $\mathrm{mm}$ stands for millimeter. 

Table 2. First- and second-stage testing results of instrumental variable analysis

\begin{tabular}{|c|c|c|c|c|c|c|c|c|c|}
\hline Test & Statistic & $\begin{array}{l}\text { All } \\
\text { IV }\end{array}$ & No $B$ & $\begin{array}{l}\text { No } \\
\text { AP }\end{array}$ & No $C$ & No L & No $T$ & $\begin{array}{c}\text { No } T \text { or } \\
\text { AP }\end{array}$ & $\begin{array}{c}\text { Only } \\
\text { B }\end{array}$ \\
\hline \multirow{4}{*}{$\begin{array}{l}\text { Under- } \\
\text { Identification }\end{array}$} & SW $\chi$ & 51.43 & 31.36 & 47.21 & 45.24 & 49.61 & 43.42 & 42.03 & 37.30 \\
\hline & $P$-value & 0.00 & 0.00 & 0.00 & 0.00 & 0.00 & 0.00 & 0.00 & 0.00 \\
\hline & $\mathbf{K P} \chi$ & 39.29 & 24.80 & 36.30 & 34.54 & 35.81 & 38.58 & 36.24 & 30.38 \\
\hline & $P$-value & 0.00 & 0.00 & 0.00 & 0.00 & 0.00 & 0.00 & 0.00 & 0.00 \\
\hline \multirow{2}{*}{$\begin{array}{c}\text { Weak- } \\
\text { Identification }\end{array}$} & CD $F$ & 10.51 & 5.02 & 13.11 & 11.46 & 13.03 & 12.41 & 16.61 & 43.43 \\
\hline & KP F & 9.97 & 7.62 & 11.48 & 11.00 & 12.06 & 10.55 & 13.67 & 36.65 \\
\hline \multirow{6}{*}{$\begin{array}{l}\text { Weak- } \\
\text { instrument- } \\
\text { robust } \\
\text { inference }\end{array}$} & AR $F$ & 19.13 & 7.46 & 23.97 & 20.85 & 23.60 & 23.33 & 30.13 & 83.85 \\
\hline & $P$-value & 0.00 & 0.00 & 0.00 & 0.00 & 0.00 & 0.00 & 0.00 & 0.00 \\
\hline & $\mathbf{A R} \chi$ & 98.73 & 30.69 & 98.64 & 85.78 & 97.12 & 95.98 & 92.64 & 85.33 \\
\hline & $P$-value & 0.00 & 0.00 & 0.00 & 0.00 & 0.00 & 0.00 & 0.00 & 0.00 \\
\hline & SW $\chi$ & 62.96 & 28.62 & 62.50 & 56.06 & 62.59 & 62.71 & 61.96 & 55.77 \\
\hline & $P$-value & 0.00 & 0.00 & 0.00 & 0.00 & 0.00 & 0.00 & 0.00 & 0.00 \\
\hline \multirow{2}{*}{ Endogeneity } & Ed-test & 27.77 & 4.84 & 44.82 & 23.45 & 28.19 & 33.66 & 46.16 & 42.63 \\
\hline & $P$-value & 0.03 & 0.03 & 0.00 & 0.00 & 0.00 & 0.00 & 0.00 & 0.00 \\
\hline \multirow{2}{*}{$\begin{array}{c}\text { Over- } \\
\text { Identification }\end{array}$} & Hsen $J$ & 13.41 & 4.30 & 5.40 & 14.69 & 12.86 & 7.62 & 2.53 & \\
\hline & $P$-value & 0.00 & 0.23 & 0.14 & 0.00 & 0.00 & 0.05 & 0.28 & \\
\hline
\end{tabular}

Note: (1) B represents Built-up Area, AP Agricultural Price Index, C Per Capita Net Income, L Average Laborers per Unit Farmland, and T Agricultural Machinery per Unit Farmland. (2) SW $\chi 2$ indicates Sanderson-Windmeijer $\chi 2$ 2tatistic; KP $\chi 2$ Kleibergen-Paap rk LM $\chi 2$ statistic; CD F Cragg-Donald (CD) Wald F statistic; KP $F$ Kleibergen-Paap Wald F statistic; AR F Anderson-Rubin (AR) Wald F statistics; AR $\chi 2$ Anderson-Rubin (AR) Wald test; Ed-test endogeneity test; Hsen $J$ : Hansen $J$ statistic. 
Table 3. Results of IV analysis of the forestland-farmland system

\begin{tabular}{|lcccc|}
\hline & 1 & 2 & 3 & 4 \\
\cline { 2 - 5 } VARIABLES & LIML & GMM & G2SLS & EC2SLS \\
\hline \multirow{3}{*}{ Farm Area } & $-1.51^{* * *}$ & $-1.51^{* * *}$ & $-1.48^{* * *}$ & $-1.22^{* * *}$ \\
& $(0.09)$ & $(0.09)$ & $(0.12)$ & $(0.09)$ \\
Timber Price Index & $0.32^{*}$ & $0.32^{*}$ & 0.31 & 0.12 \\
& $(0.18)$ & $(0.18)$ & $(0.24)$ & $(0.19)$ \\
Gross Value of Forestry Outputs & -0.00 & -0.00 & -0.00 & 0.00 \\
& $(0.00)$ & $(0.00)$ & $(0.00)$ & $(0.00)$ \\
Natural Forest Protection Program & $56.31^{* * *}$ & $56.31^{* * *}$ & $54.25^{* * *}$ & $31.79^{* *}$ \\
& $(13.59)$ & $(13.59)$ & $(19.80)$ & $(15.15)$ \\
Total Population & $-0.59^{* * *}$ & $-0.59^{* * *}$ & $-0.61^{* * *}$ & $-0.55^{* * *}$ \\
& $(0.07)$ & $(0.07)$ & $(0.14)$ & $(0.11)$ \\
Distance to Nearby Markets & & & $104.11^{* * *}$ & $86.79^{* * *}$ \\
& & & $(11.21)$ & $(8.36)$ \\
Number of Forest Farms & & & $349.02^{* * *}$ & $323.44^{* * *}$ \\
& & & $(22.02)$ & $(16.82)$ \\
Constant & & & $-968.99^{* * *}$ & $-819.36^{* * *}$ \\
& & & $(289.52)$ & $(226.72)$ \\
$R^{2}$ within & & & & \\
$R^{2}$ between & & & 0.85 & 0.86 \\
$R^{2}$ overall & 0.74 & 0.74 & 0.70 & 0,76 \\
\end{tabular}

Note: (1) Models 1-2 were estimated using different FE estimators. The Limited Information Maximum Likelihood (LIML) estimator (Staiger and Stock, 1994) (Model 1) is believed to outperform the Generalized Method of Moments (GMM) estimators in finite samples (Cameron and Trivedi, 2009; Murray, 2006). However, Bekker and Ploeg (2005) and Hausman et al. (2007) argued that the LIML is inconsistent with the presence of heteroskedasticity when the number of instruments is large. The widely applied GMM estimation methods have the virtue of avoiding unnecessary structure assumptions in the data-generating process, and thus the specification of a particular distribution of the error terms (Model 2). The two-step GMM constructs a weighting matrix with a consistent estimate of the parameters in its first step (Windmeijer, 2005). So, Model 2 is robust to arbitrary heteroskedasticity. Models 3-4 apply RE estimators in conjunction with the IV method. Model 3 was fit with the Generalized TwoStage Least Squares Random Effects (G2SLS RE) estimator, and Model 4 was based on Baltagi's Error Component two-Stage Least Squares Random Effects (EC2SLS RE) estimator (Schaffer, 2012). The G2SLS and EC2SLS estimators differ in how they construct the GLS instruments. The traditional G2SLS estimator passes each exogenous variable in the explanatory variable through the feasible GLS transformation, while Baltagi's EC2SLS spans the set of instruments used by including the group means of each variable.

(2) Standard errors are in parentheses, with $*, * *$, and $* * *$ indicating the significance levels of $90 \%, 95 \%$, and $99 \%$, respectively. 
Table 4. Results of 3SLS analysis of the "farmland-forestland-wetland" system

\begin{tabular}{|c|c|c|c|c|}
\hline VARIABLES & $\begin{array}{l}\text { Expected } \\
\text { Sign }\end{array}$ & $\begin{array}{c}(1) \\
\text { Forestland }\end{array}$ & $\begin{array}{c}(2) \\
\text { Farmland }\end{array}$ & $\begin{array}{c}\text { (3) } \\
\text { Wetland }\end{array}$ \\
\hline Farmland & - & $\begin{array}{c}-1.37 * * * \\
(-0.05)\end{array}$ & & $\begin{array}{c}-0.64 * * * \\
(-0.07)\end{array}$ \\
\hline Wetland & - & $\begin{array}{c}-0.49^{* * * *} \\
(-0.1)\end{array}$ & & \\
\hline Timber Price Index & - & $\begin{array}{c}0.07 \\
(-0.1)\end{array}$ & & \\
\hline Population & - & $\begin{array}{c}-0.42 * * * \\
(-0.05)\end{array}$ & & \\
\hline NFPP & + & $\begin{array}{c}18.82 * * \\
(-7.97)\end{array}$ & & \\
\hline Forestland & - & & & $\begin{array}{c}-0.79 * * * \\
(-0.07)\end{array}$ \\
\hline Irrigation Area & - & & & $\begin{array}{l}-3.15^{* * * *} \\
(-0.22)\end{array}$ \\
\hline Average Annual Precipitation & + & & & $\begin{array}{l}-0.02 * \\
(-0.01)\end{array}$ \\
\hline Average Annual Temperature & - & & & $\begin{array}{c}-1.97 * * * \\
(-0.38)\end{array}$ \\
\hline Rural Net Income & + & & $\begin{array}{c}0.10^{* * *} \\
(-0.02)\end{array}$ & \\
\hline Agricultural Population & + & & $\begin{array}{c}-0.66 * * * \\
(-0.2)\end{array}$ & \\
\hline Farming Machinery Power & + & & $\begin{array}{c}0.22 * * * \\
(-0.06)\end{array}$ & \\
\hline Constant & & $\begin{array}{c}3,829.26^{* * *} \\
-85.43\end{array}$ & $\begin{array}{c}1,836.92 * * * \\
-44.32\end{array}$ & $\begin{array}{c}2,386.06^{* * * *} \\
-197.67\end{array}$ \\
\hline $\begin{array}{l}\text { Number of Observations } \\
R^{2}\end{array}$ & & $\begin{array}{l}296 \\
0.89\end{array}$ & $\begin{array}{l}296 \\
0.17\end{array}$ & $\begin{array}{l}296 \\
0.63\end{array}$ \\
\hline
\end{tabular}

Note: The signs indicate how the dependent variable is expected to be associated with the independent variables. Standard errors are in parentheses and *,**, and $* * *$ indicate the significance levels of $90 \%, 95 \%$, and $99 \%$, respectively. 